\title{
Learning to resist the urge: a double-blind, randomized controlled trial investigating alcohol-specific inhibition training in abstinent patients with alcohol use disorder
}

Raphaela M. Tschuemperlin ${ }^{1,2+}$, Maria Stein ${ }^{1,3^{*}+}$ (D), Hallie M. Batschelet ${ }^{1}$, Franz Moggi ${ }^{1}$ and Leila M. Soravia ${ }^{1,2}$

\begin{abstract}
Background: Alcohol use disorder (AUD) leads to a significant individual and societal burden. To achieve higher therapy success rates, therapeutic interventions still need to be improved. Most current neuroscientific conceptualizations of AUD focus on the imbalance between an enhanced automatic reaction to alcohol cues and impaired inhibition. Complementary to traditional relapse prevention strategies, novel computerized training interventions aim to directly alter these processes. This study tests a computerized alcohol-specific inhibition training in a large clinical sample and investigates its effects on behavioral, experimental and neurophysiological outcomes. It also analyzes whether variations in inhibition difficulty and/or endogenous cortisol levels during training impact these effects.
\end{abstract}

Methods: This is a double-blind, randomized controlled trial $(\mathrm{RCT})$ with 246 inpatients with AUD participating. After baseline assessment, participants are randomly assigned to one of three computerized Go-NoGo-based inhibition training interventions (two alcohol-specific versions with different Go/NoGo ratios, or neutral control training) and one of two intervention times (morning/afternoon), resulting in six study arms. All patients perform six training sessions within 2 weeks. Endogenous cortisol is measured in 80 patients before and after the first training session. Inhibitory control and implicit associations towards alcohol are assessed pre and post training, at which point electroencephalography (EEG) is additionally measured in 60 patients. Patients' alcohol consumption and relevant psychological constructs (e.g., craving, self-efficacy, treatment motivation) are measured at discharge and at 3-, 6and 12-month follow-ups. Fifty healthy participants are assessed (20 with EEG) at one time point as a healthy control group.

Discussion: This study investigates the effects of a computerized, alcohol-specific inhibition training for the first time in patients with AUD. Results should give insight into the effectiveness of this potential add-on to standard AUD treatment, including proximal and distal measures and effects on behavioral, experimental and neurophysiological measures. Information about working mechanisms and potential optimizations of this training are gathered through variations regarding difficulty of inhibition training and training time. This study may thus contribute to a deepened understanding of AUD and the improvement of its evidence-based treatment.

\footnotetext{
* Correspondence: maria.stein@upd.unibe.ch

Raphaela M. Tschuemperlin and Maria Stein are shared first authorship

${ }^{1}$ Translational Research Center, University Hospital of Psychiatry, University of

Bern, Bern, Switzerland

${ }^{3}$ Department of Clinical Psychology and Psychotherapy, Institute of

Psychology, University of Bern, Bern, Switzerland

Full list of author information is available at the end of the article
}

(c) The Author(s). 2019 Open Access This article is distributed under the terms of the Creative Commons Attribution 4.0 International License (http://creativecommons.org/licenses/by/4.0/), which permits unrestricted use, distribution, and reproduction in any medium, provided you give appropriate credit to the original author(s) and the source, provide a link to the Creative Commons license, and indicate if changes were made. The Creative Commons Public Domain Dedication waiver (http://creativecommons.org/publicdomain/zero/1.0/) applies to the data made available in this article, unless otherwise stated. 
(Continued from previous page)

Trial registration: ClinicalTrials.gov, ID: NCT02968537. Registered on 18 November 2016.

Keywords: Alcohol use disorder, Alcohol-specific inhibition training, EEG, Cortisol, Go-NoGo Task (GNG), Stop-Signal Task (SST), Implicit Association Test (IAT), Residential treatment, Drinking outcome

\section{Background}

Alcohol use disorder (AUD) is a major public health problem which has a substantial impact on patients' psychological, physiological and social functioning [14]. Severe AUD often remains a lifelong condition due to patients' susceptibility to relapse [5-7]. Despite the development of valuable treatment programs [8, 9], one third of patients relapse within 1 year after treatment, highlighting the need for effective new interventions to be added to these programs.

Current models of substance use disorders (SUDs) are based on neuroscientific research into subcortical alterations (e.g., [10-12]) and psychological investigations on implicit processes [13], and postulate on an imbalance between subcortical, implicit processes and cortical control processes. Briefly, these models assume that automated (subcortical) cue-reactivity is enhanced, thus leading to a strong drive to consume, while the opponent (cortical) executive control is weakened, making it difficult to inhibit this impulse (e.g., [11, 14-16]). The neuroscientific findings that underlie these models include enhanced reactivity to substance-related cues in brain regions related to reward prediction and saliency processing (e.g., nucleus accumbens, amygdala), habits and motivation (dorsal striatum, orbitofrontal cortex) and alterations in brain regions related to inhibitory control (dorsolateral prefrontal cortex, inferior frontal cortex and anterior cingulate cortex) [17, 18]. There is an extensive body of literature indicating that SUD is associated with impaired performance in inhibitory control tasks [1924]. Until recently, these tasks did not differentiate between inhibition in a substance-related versus neutral context. However, this distinction seems to be clinically relevant, given that the central malfunction leading to relapse is the inability to exert inhibitory control in a substance-related context. Recent studies have suggested that alcohol-related inhibition demands additional neuronal resources in patients with AUD and heavy drinkers [25-28].

To translate the findings of impaired inhibitory control and enhanced cue-reactivity into a therapeutic context, an inhibition training for eating disorders [29-31] has been adapted into a novel alcohol-specific inhibition training and introduced into the field of AUD research $[32,33]$. During this short, computerized, behavioral training, alcohol-related stimuli are consistently paired with a stopping response. Such an intervention might thus improve inhibitory control by training it on an explicit as well as a habitual level and possibly reduce cuereactivity through stimulus devaluation.

The effect of one or two of these training sessions on alcohol consumption has been tested in regular drinkers [34, 35] and non-clinical, heavy drinkers [32, 33, 36, 37]. When alcohol consumption was assessed immediately after the training session, two studies found decreased consumption $[35,36]$, one study observed a nonsignificant trend in that direction [33], another study reported longer latency until participants took the first sip [37], and one study found no effects [34]. Of those studies assessing alcohol consumption 1 or 2 weeks post intervention, three studies reported decreased consumption after alcohol-specific inhibition training [32, 33, 37]. Note, however, that in two of these studies, the intervention was compared to a control condition, which could potentially have fostered alcohol consumption within the control group [32, 33]. Two other studies found no significant effects [34, 35]. In summary, while the effects of this training are inconsistent in non-clinical samples, it might be more effective in clinical populations where (1) the motivation to change drinking behavior is higher and (2) the impairment targeted by the training is assumed to be more pronounced at baseline. Therefore, it is important to test the feasibility and efficacy of the training in clinical populations with AUD. The present randomized controlled, double-blind study aims to close this gap, and includes follow-up measurements of drinking behavior and related concepts up to 12 months after treatment discharge, allowing assessment of potential clinically relevant long-term effects.

There are two putative working mechanisms by which alcohol-specific inhibition training is thought to be effective. The first is through enhancing inhibitory capacities in the context of alcohol-related cues, which can be assessed with inhibitory tasks, such as the Go-NoGo Task (GNG) or the Stop-Signal Task (SST). The second putative working mechanism regards devaluation of the stimuli. It is based on the Behavior Stimulus Interaction Theory [38], which states that the repeated stopping response to the rewarding (alcohol, in this context) stimuli causes a devaluation thereof $[31,33]$. This mechanism is thus thought to alter the automatically attributed appeal of alcohol-related stimuli, an effect which can be measured with the Implicit Association Test (IAT). 
With respect to the devaluation mechanism, the first two studies were consistent with predictions of the Behavior Stimulus Interaction Theory in their reports that participants' implicit attitudes shifted towards a more negative evaluation of alcohol-related stimuli after alcohol-specific inhibition training [32, 33]. However, this finding could not be replicated in the four subsequent studies [34-37].

In regard to an inhibition-related working meachanism, those studies using the respective measures found no effects of GNG-based inhibition training on an SST [32, 37] nor flanker task [34]. However, these tasks measure slightly different inhibitory aspects (e.g., action cancellation in case of the SST) than the one affected during the GNG-based training (action restraint). The only study which assessed inhibitory functioning in the same form as targeted during training (i.e., measurement of inhibitory control with a GNG after a GNG-based training) reported no effects on reaction times during Go trials. Unfortunately, data on errors of commission (EOCs), which are a commonly used indicator of inhibitory capacities and an essential and proximal experimental outcome of a GNG-based inhibition training, were not reported in this study [36] and are thus still missing. Another important aspect concerns $\mathrm{Go} / \mathrm{NoGo}$ ratio incorporated during training sessions. With one exception [34], most studies emloyed equiprobable GNG tasks with a Go/NoGo ratio of 50/50 during the training session. Such a ratio is unusually balanced for GNG tasks, where NoGo responses usually only make up $10-20 \%$ of the trials (e.g., [23, 24, 39]) in order to establish a high tendency to respond while making inihibition more demanding. Thus, it is possible that these versions failed to create the context of a prepotent Go response, in which inhibition could effectively be trained. The present study aims to extend prior research on potential working mechanisms by comparing two versions of this alcohol-specific inhibition training differing solely in the Go/NoGo ratio (thus in inhibition difficulty) and by comparing these versions' effects on inhibitory capacities as well as on implicit associations.

With regard to other clinically important psychological variables, research has shown that outcome expectancies [40], self-efficacy to remain abstinent [41], motivation to change alcohol use [42] and craving [43] predict drinking outcomes at 1-year follow-up. These variables might thus act as potential mediators of effects in a clinical study. Furthermore, if the alcohol-specific inhibition training influences implicit associations towards alcohol, it might also affect explicit expectancies and/or subjective craving. The present study will, therefore, include these variables as potential outcomes and mediators in explorative analyses.

Taken together, the present study investigates the effects of an alcohol-specific inhibition training for the first time in a clinical sample using a randomized controlled, double-blind design with long follow-up periods. In doing so, the study contributes to research on potential working mechanisms by comparing two versions of the training which differ only in the Go/NoGo ratio and by the comparison of their effects on inhibitory functions and implicit associations. Explorative analyses will target psychological variables, such as craving, outcome expectancies, selfefficacy and motivation to change alcohol use. As the training's rationale is anchored in neuroscientific research, we will also monitor neurophysiological effects with multi-channel electroencephalography (EEG) in order to investigate whether the training changes the neurophysiological correlates of alcohol-specific inhibition and/or implicit associations. Finally, prior research has shown that endogenous cortisol is a consolidation enhancer [44], which peaks in the morning $[44,45]$ and has been shown to improve effects of other learning-based therapies [46]. Since training procedures rely on learning processes affected by endogenous cortisol, we are, therefore, interested in whether its levels influence training effects.

\section{Study aim}

In the present project, the Inhibition Training (INTRA) study, 246 recently abstinent patients with AUD attending an inpatient treatment program will be randomly assigned to one of two alcohol-specific inhibition training groups (each with a different Go/NoGo ratio) or to a control group. Our aim is to examine whether variations of inhibition training have a positive effect on drinking behavior, implicit attitudes, and neurophysiological reactivity to alcohol-related stimuli. Thus, a subgroup of patients will additionally undergo EEG recording before and after the intervention so that neurophysiological effects of the training can be assessed and related to clinical outcomes. In addition, 50 healthy controls (with EEG measurement of 20) will be assessed once to compare patients' pre-training data. Since training effects rely on learning processes, the influence of endogenous cortisol level (a consolidation enhancer, which peaks in the morning and decreases in the course of the day [44]) on training outcome will be investigated by varying the time of day in which the training is performed. All patients' inhibition and implicit associations towards alcohol will be measured immediately before and after the training. We will also measure the training's effects on proximal outcome variables (e.g., implicit associations, inhibitory control, abstinence-related self-efficacy, craving) post training, and distal outcome variables (e.g., percentage of days abstinent - PDA; heavy-drinking days HDD; and time to first drink - TFD) at 3-, 6- and 12month follow-ups.

For the first time, this trial will investigate the therapeutic potential of an alcohol-specific inhibition training 
as a therapeutic supplement in a sample with patients suffering from severe AUD. In doing so, the impact on training efficacy of time of training and Go/NoGo ratio will additionally be investigated and the underlying neurophysiological mechanisms of the training elucidated. Moreover, potential AUD-related psychological constructs will be explored. The project thus aims to contribute to the improvement of the evidence-based treatment of AUD.

\section{Research questions}

Based on prior research, the following five research questions are examined:

1. Does the alcohol-specific inhibition training (Alc-IT, compared to the control intervention) reduce PDA and HDD and/or extend the time to first drink (TFD) at 3-months' follow-up (primary outcomes)?

2. What is the effect of the Alc-IT on behavioral experimental parameters?

(a) Does Alc-IT decrease positive implicit associations compared to the control training?

(b) Does Alc-IT enhance response inhibition compared to the control training?

3. Are the neurophysiological correlates of alcoholspecific inhibition and implicit associations towards alcohol changed by Alc-IT?

4. Does endogenous cortisol moderate the effect of the Alc-IT?

5. In addition, explorative questions investigate whether the effects of the training on outcomes are mediated by AUD-related psychological constructs, such as alcohol-related self-efficacy, craving or motivation

\section{Methods}

\section{Study design and setting}

The present study is a multicenter, double-blind, randomized controlled trial (RCT) with six conditions. The interventions consist of two alcohol-specific inhibition trainings (with different Go/NoGo ratios) and one control inhibition training that is not context specific. In each version of the training, six sessions will be performed over the space of 2 weeks. Next to the three versions of the training, different samples will perform the training in different times of the day (morning/afternoon), resulting in a total of six conditions. Between the three study sites, 246 abstinent inpatients with AUD will be recruited. To compare our patient sample to the healthy population, we will measure 30 (behavioral) and 20 (EEG) healthy participants at one point in time. The duration of the study from the first inclusion to the last participant's follow-up is 36-40 months. Recruitment, randomization, and baseline measurements (T1) will take place at one of the three study sites at the beginning of the regular inpatient program. All patients will have undergone detoxification prior to entering this inpatient program. Pre-training assessment (T2) is usually performed by the end of the second week or at the beginning of the third week of the inpatient stay and is followed by the 2 weeks, during which the six training sessions of the intervention or the control training are performed. Post-training assessment (T3) takes place 1 to 4 days after the last training session. At discharge (T4), the last measurement during inpatient program is performed. The duration of the inpatient stay typically varies between 8 and 12 weeks, depending on individual and institutional factors. Follow-up assessments take place 3 (T5), 6 (T6) and 12 (T7) months after discharge and consist of a questionnaire battery and a telephone interview (see also "Procedure" and Fig. 1).

\section{Participants \\ Patients}

We will screen all patients who previously completed a detoxification and then entered an alcohol-specific inpatient treatment program at one of three specialized addiction treatment centers in Switzerland, namely the Suedhang Hospital (Bern); the Forel Hospital (Zuerich) and the Psychiatric Hospital of Muensingen (Bern). Inclusion criteria are age 18-60years and abstinence from alcohol for at least 4 weeks prior to the first training session. Exclusion criteria are other main psychiatric diagnoses than AUD (comorbidities are allowed as long as AUD is considered to be the main diagnosis), other severe SUD (except nicotine; Drug Use Identification Test (DUDIT $[47,48]) \geq 25$ per substance), no diagnosed neurocognitive problems (e.g., Korsakoff syndrome) in the medical history, current medical conditions preventing participation (e.g., acute infectious diseases), the inability to read and understand the participant's information and the enrollment of an investigator, their family members, employees and other dependent persons. Written informed consent will be obtained from all patients at the beginning of the study.

\section{Healthy controls}

In order to compare behavioral data of the patient sample to that of a healthy population, 50 healthy controls will be measured at one point of time (20 with EEG). Inclusion criteria for healthy controls are age 18-60 years, nonproblematic drinking behavior (Alcohol Use Disorders Identification Test (AUDIT [49]) $<8$; Alcohol Use Disorder Scale (AUD-S [50]) $<2)$ ), and no signs of psychopathology (Brief Symptom Check List (BSCL [51, 52],) GSI $\left._{\text {t-value }} \leq 63\right)$. Exclusion criteria consist of current treatment for a psychiatric diagnosis and/or psychopharmacological medication, treatment for SUD in the past, problematic substance use (except nicotine; DUDIT $\geq 8$ per substance, e.g., cannabis), neurocognitive problems, 


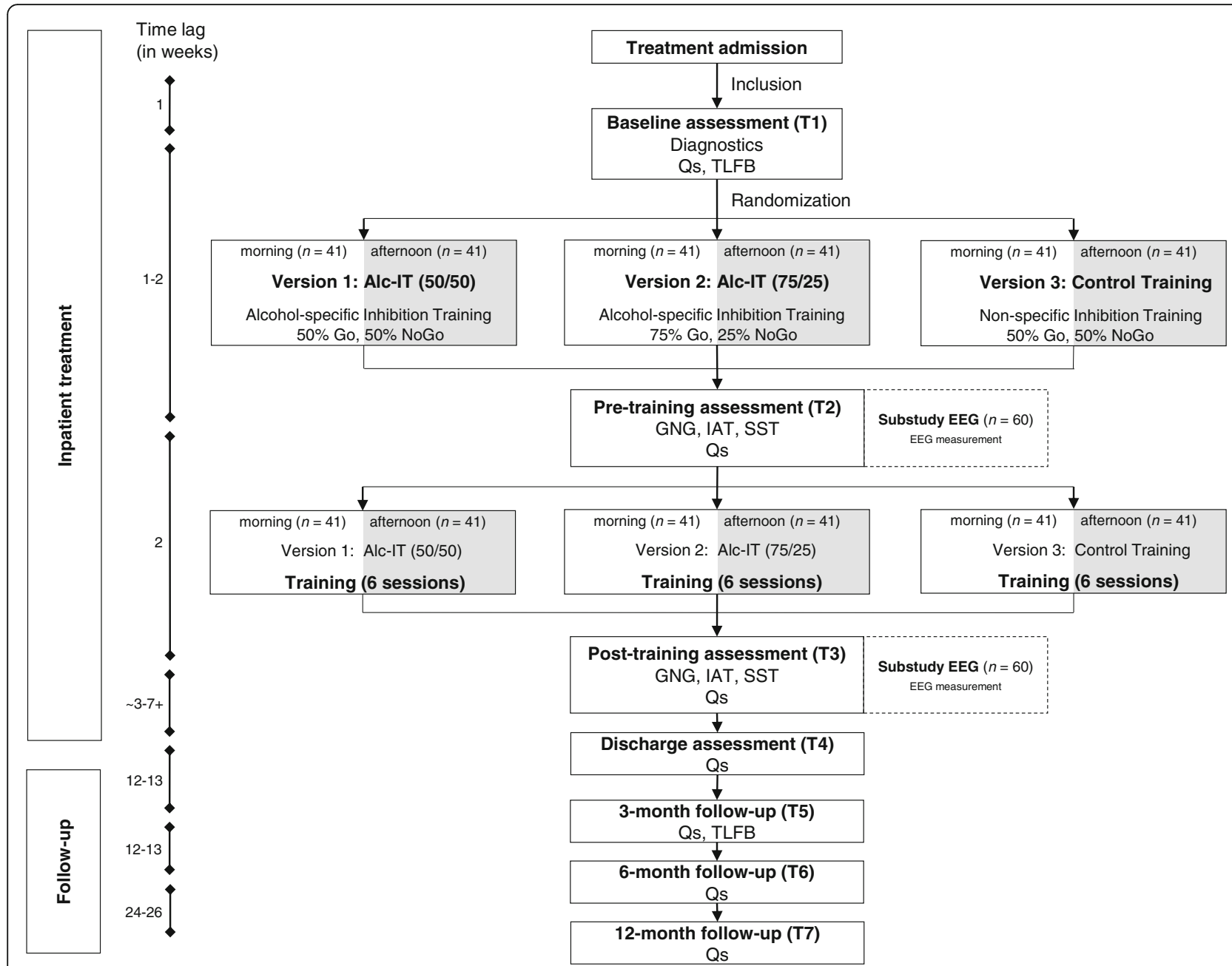

Fig. 1 Study design of the INTRA study. Note that for the cortisol substudy, salvia-cortisol samples will be collected before and after the first training session. Alc-IT alcohol-inhibition training, EEG electroencephalography, GNG Go-NoGo Task, IAT Implicit Association Test, INTRA Abbreviation of the study name: INhibition TRaining in Alcohol use disorder, n sample size, SST Stop-Signal Task, TLFB Timeline-follow-back, Q questionnaire

poor health conditions, the inability to read and understand the study information. In the substudy EEG, additional exclusion criteria are the occurrence of AUD in first-degree relatives and hearing impairments. Written informed consent will be obtained from all healthy controls prior to inclusion. For a tabular overview of all in- and exclusion criteria, see Additional file 1.

\section{Stimulus material}

\section{Stimuli for training, GNG and IAT}

A total of 40 pictures of alcoholic beverages, water and neutral objects were created by the study team. All pictures were photographed with a high-resolution camera (Nikon D810, Nikon Inc., Tokyo, Japan) in a neutral setting with a white background and the same light conditions (two spotlights). Water pictures are the same for all participants, whereas alcohol pictures will be matched to the individual's drink of choice. For this purpose, three sets with either beer (seven lager, one wheat), wine (two red, two white, two rosé, two sparkling wines) or spirits (two vodka, two whiskey, two liquor, one gin, one tequila) were generated. Each of the four beverage sets includes eight pictures of brands commonly consumed in Switzerland, with all pictures comprising a bottle or can and a full beverage-specific glass (for examples, see Additional file 2).

The eight neutral stimuli are everyday objects (e.g., a flashlight plus battery) and were selected by complexity, shape and familiarity. All pictures were edited with GIMP software (GIMP 2.8.18, retrieved from https:// www.gimp.org) and adjusted for size, centralization, brightness and background to ensure picture similarity.

\section{Stimuli for SST}

For the third task, stimulus material consist of 16 pictures $(344 \times 400$ pixel $)$ of a database and are characterized by 
their alcohol relatedness, valence, craving, arousal, luminance, colors and visual complexity [53]. Four pictures of each drink of choice (beer, wine and spirits), shot in (social) daily situations within a building, and four pictures of everyday objects (e.g., a hydrant) located outdoors, were selected. This additional stimulus material was chosen to test for generalization of the effect of our intervention to a novel inhibition task and to new stimuli.

\section{Intervention}

Participants in both versions of the Alc-inhibition training (Alc-IT) are, as the name suggests, trained in alcoholspecific inhibition: pictures of alcoholic beverages will be consistently paired with a NoGo cue, while Go cues will be distributed among the other picture types (water, neutral). In contrast, for patients in the control training group, all three picture types will be paired equally often with NoGo cues and Go cues (see Table 1).

- Alc-IT (50/50): the first training group will operate with a Go/NoGo ratio of 50/50, as implemented in prior studies [32, 33]: This original version of the Alc-IT will include 80 alcoholic NoGo trials as well as 80 non-alcoholic Go trials. In order to match both Alc-IT versions in training length while keeping the number of Alc-NoGo pairings constant, an additional 80 neutral Go trials and 80 neutral NoGo trials were included

- Alc-IT (75/25): the second version of the Alc-IT will operate with a Go/NoGo ratio of $75 / 25$. It will equally include 80 alcoholic NoGo trials and 80 non-alcoholic Go trials, but contrary to Alc-IT (50/50) 160 neutral Go trials will complete the set. Both Alc-IT versions thus include the same number of Alc-NoGo pairings and are of the same length, but differ in their Go/NoGo ratio and thus in the difficulty regarding inhibition control

- Control training: the control group will receive a training that consists of 80 non-alcoholic, 80 alcoholic, and 160 neutral trials. This control training is thus a non-specific inhibition training which is of equal length to other two groups and includes the same number of alcohol-related pictures in it, but all pictures will appear with equal

Table 1 Distribution of trial types in the three training versions

\begin{tabular}{|c|c|c|c|c|c|c|}
\hline \multirow[b]{3}{*}{ Picture types } & \multirow{2}{*}{\multicolumn{2}{|c|}{$\frac{\text { Alc-IT }(50 / 50)}{\text { Trial type }}$}} & \multirow{2}{*}{\multicolumn{2}{|c|}{$\frac{\text { Alc-IT }(75 / 25)}{\text { Trial type }}$}} & \multirow{2}{*}{\multicolumn{2}{|c|}{$\frac{\text { Control training }}{\text { Trial type }}$}} \\
\hline & & & & & & \\
\hline & Go & NoGo & Go & NoGo & Go & NoGo \\
\hline Alcohol & - & 80 & - & 80 & 40 & 40 \\
\hline Water & 80 & - & 80 & - & 40 & 40 \\
\hline Neutral & 80 & 80 & 160 & - & 80 & 80 \\
\hline Total trials & 320 & & 320 & & 320 & \\
\hline
\end{tabular}

probabilities as Go or NoGo trials while the Go/ NoGo ratio is kept at $50 / 50$

All three versions of the inhibition training were programmed with Inquisit 5 (Version 5.0.5.0., Millisecond Software, Inc., Seattle, WA, USA). They are based on the script by Houben, Havermans [32], Houben, Nederkoorn [33], which was gratefully received by the authors and adapted to their own version. Go and NoGo cues are represented by the letter " $p$ " or " $f$ " next to one of the four corners of the alcohol, water or neutral pictures $(1047 \times 1080$ pixel), whereby the assignment to the letters will be counterbalanced across participants. Participants will be instructed to press the space bar when a Go cue has been displayed and to refrain from pressing it when a NoGo cue has appeared. Each version of the training lasts approximately $13 \mathrm{~min}$ and consists of 320 trials, which are presented in a randomized order. A trial includes the simultaneous presentation of a picture and a cue (paired in accordance with the intervention version) and is visible on screen for $1500 \mathrm{~ms}$. Participants are instructed to respond as fast as possible, unless the picture is paired with a NoGo cue. $500 \mathrm{~ms}$ after the (non)response visual feedback will be given, with a green circle indicating a correct (non)response, and a red cross indicating an incorrect (non)response. Based on data by Eberl et al. [54], which compared learning outcome after varying numbers of sessions of computerized training in AUD patients, participants will perform six training sessions.

\section{Interviews and questionnaires Demographics}

Relevant demographics (e.g., age, gender, education) as well as relevant information about past AUD treatment or other mental health problems will be assessed.

\section{Diagnostics}

The German version of the semi-structured interview of the Diagnostic Expert System for Psychiatric Disorders (DIA-X, adapted to the Diagnostic and Statistical Manual of Mental Disorders (DSM-5); [55])) specifically for AUD will be performed by a trained member of the study team. The original DSM-IV version was modified to meet the DSM-5 criteria, whereby the symptom craving was added and the question about legal issues was removed.

\section{Alcohol use disorder and other substance use}

The screening questionnaire Alcohol Use Disorders Identification Tests (AUDIT; [49]) from the World Health Organization (WHO) consists of 10 items on recent alcohol use, AUD symptoms, and alcohol-related problems.

With the Alcohol Use Disorder - Scale (AUD-S; [50]; adapted to DSM-5), self-rated AUD symptoms 
are measured, whereas this adapted version additionally includes craving as a criteria.

To assess patients' alcohol use in the last 90 days prior to their current detoxification, an adapted version of the Health and Daily Living Form (HDL; [56]) will be used, which was also employed in a large, Swiss multicenter study $[57,58]$. Patients will be asked about their consumption frequency and quantity of beer, wine, liquor and spirits, resulting in total number of standard drinks (SD; 1 $\mathrm{SD}$ equates to $3 \mathrm{dl}$ beer, $1 \mathrm{dl}$ wine, $2 \mathrm{cl}$ spirits/liquor, or 10 $\mathrm{g}$ of pure alcohol) consumed per day. Separate items assess the PDA and the number of HDD for the last 90 days.

To measure the drinking behavior for each of the past 90 days, the Timeline Follow-back (TLFB; [59, 60]) method will be performed, which will be administered by an interview (face-to-face at $\mathrm{T} 1$ or telephone at $\mathrm{T} 5$ ) with a trained member of the study team. As in the HDL, the amount of alcohol per day will be assessed in standard drinks per day, but in contrast is conducted through a guided, standardized interview. The TLFB provides a report of drinking pattern, including PDA, HDD and TFD.

With the Drug Use Identification Test (DUDIT; [47, 48]), participants will be screened for substances (except nicotine) other than alcohol. Patients with other severe substance use and healthy controls with a problematic substance use are not eligible for this trial (see also "Inclusion/exclusion" criteria).

\section{Alcohol-related constructs}

Alcohol craving will be measured by the Obsessive Compulsive Drinking Scale, (OCDS-G; [61]). The items of the OCDS-G are divided into two subscales: control and consequences, and drinking obsessions.

As a second measure for craving, three specific questions will be asked $[57,58]$, which are scored from 0 (non-existent or never) to 10 (very strongly or always): "How strong was your urge to drink alcohol (on average) during the past 7 days?"; "Think of the moment during the past 7 days, in which the urge to consume alcohol was the highest. How strong was the urge?"; and "How often did you have the urge to drink alcohol during the past 7 days?"

Motivation to change alcohol use will be assessed with the Stages of Change Readiness and Treatment Eagerness Scale (SOCRATES; [62]), whereby only the subscale Taking Steps will be used. It indexes whether the person has already taken action to positively change their drinking behavior.

A second measure for motivation consists of three items on an 11-point Likert scale, summed up as Motivation [41, 63, 64]. Inspired by the framework of motivational interviewing [64], the first question "How important is it for you not to drink alcohol? What do you think about that at this very moment?" [63] will be followed by the statement "I will do everything to get my alcohol problem under control." [64]. Third, general self-efficacy will be assessed with one question: "How confident are you that you will be completely abstinent in one year from now?" [41].

A broader concept of alcohol-specific self-efficacy will be measured with the Alcohol Abstinence Self-Efficacy Scale (AASE-G [65]), which assesses the patients' expectations concerning their ability to remain abstinent from alcohol in specific high-risk situations.

Positive and negative alcohol outcome expectancies are quantified with the Comprehensive Alcohol Expectancy Scale (CAEQ [66, 67]). A reduced version [67] will be used to assess five dimensions of alcohol expectancies: social assertiveness and positive affect; tension reduction; cognitive impairment and physical discomfort; aggression; and sexual enhancement.

As has been done before [57, 58], Drinking Goals will be assessed by asking the patients whether their personal drinking goal is (1) total abstinence and hence no future alcohol use, (2) abstinence with occasional lapses, or (3) controlled and responsible drinking.

Finally, with a self-created Discharge Questionnaire, all patients will be asked about occurring relapses during their treatment. Participants will be informed that this information is confidential and will not be shared with the staff of the relevant hospital.

\section{Psychopathology}

General psychopathology will be assessed with the Brief Symptom Check List, (BSCL, formerly BSI; [51, 52]), which comprises of nine primary symptom dimensions (e.g., depression, anxiety, hostility) and three global indices (e.g., global severity index).

Apart from this general measure, several screenings for specific psychopathological syndromes which are often comorbid with AUD will be implemented: the intensity of anxiety symptoms will be assessed with the Beck Anxiety Inventory (BAI $[68,69])$, and for qualification of the severity of depressive symptoms, the Beck Depression Inventory (BDI-II [70, 71]) will be administered. The ADHD Self Report Scale (ASRS-V1.1 [72, 73]) assesses symptoms of Attention Deficit and Hyperactivity Disorder (ADHD). The PTSD Screening Scale (PSS; [74, 75]) qualifies symptoms of posttraumatic stress disorder (PTSD).

Additionally, stress (due to loss or experience of negative events) and coping will be assessed with the Stress and Coping Inventory (SCI [76]). Subjectively perceived quality of life will be measured with three subscales (global scale, physical and psychological health) from the short version of the World Health Organization Quality of Life questionnaire (WHOQOL-BREF [77, 78]). 


\section{Traits}

Relevant traits linked to AUD are of special interest: Impulsivity will be measured with the short questionnaire Scale for Impulsive Behavior (I-8 [79]). Sensation seeking will be qualified with the Need Inventory of Sensation Seeking (NISS [80]), which includes two subscales (need for stimulation and avoidance of rest). To assess Antisocial Personality Disorder (ASPD), an adapted questionnaire from the Mini-International Neuropsychiatric Interview (M.I.N.I. [81], also employed in the C-Surf cohort study [82]) will be used. To quantify motivational systems (activation/inhibition), underlying behavior and affect, the Behavioral Inhibition System/Behavioral Approach System Scales (BIS/BAS [83]) will be used as in the C-Surf cohort study [84] in a version adapted from the validated German version [85].

\section{Other}

Additionally, two other measures will be used: experienced emotions as well as the capability of the participant to experience and regulate these emotions will be measured with the Emo-Check [86, 87]. The Trail Making Test $A$ and B (TMT A \& B [88]) screens for neuropsychological executive function by assessing visual attention and task switching. Previous research with preclinical samples indicates that executive functions could influence the relationship between alcohol-related implicit cognitions and addictive behaviors $([89,90]$, but see [54]). Consequently, the TMT will be used as a covariate in the statistical analyses.

\section{Experimental tasks}

Both the computerized experimental tasks and response logging are programmed and administered with E-Prime 2.0 (EP2Pro2.0.10.356, Psychology Software Tools, Sharpsburg, PA, USA). With the picture size $(344 \times 400$ pixel $)$ being equal for all three tasks, the set of alcohol-related pictures will be matched to the individual's drink of choice (beer, wine, or spirits).

\section{Go-NoGo Task (GNG)}

This task measures response inhibition in both an alcohol-specific and a neutral context. In the modified version of Stein et al. [25], eight pictures of alcoholic beverages (beer, wine, or spirits, according to the participants drink of choice) and eight neutral beverages (water) are presented on screen at a presentation rate of $1 \mathrm{~Hz}$. The pictures are displayed on-screen for $900 \mathrm{~ms}$ and the interstimulus interval is $100 \mathrm{~ms}$. Participants are instructed to click a button as soon as a stimulus appears on screen (Go trial) unless the same stimulus appears twice in a row (NoGo trial). Each of the 16 pictures will be presented 60 times during the task: 52 times as a Go trial and eight times as a NoGo trial, resulting in a Go/NoGo ratio of 6.5.
This ratio is intended to establish a high tendency to respond, making action restraint difficult. In total, the whole experiment thus includes 960 trials (416 neutral Go trials, 416 alcohol-related Go trials, 64 neutral NoGo trials, and 64 alcohol-related NoGo trials), which are presented in a pseudorandomized order, controlling for position, sequential order, and requiring a minimum of two Go trials between two NoGo trials. Half way through, participants are allowed a pause of a self-determined length. The whole task takes approximately 18 min to complete.

\section{Stop-Signal Task (SST)}

As a second measure of response inhibition, a Stop-Signal Task (SST) will be performed, which includes four pictures of alcoholic beverages located inside a building and four neutral pictures of objects located outside. After a fixation cross, which lasts $460 \mathrm{~ms}$, the individual pictures will appear on a computer screen and participants will be instructed to press the button "a" (left) or "l" (right) as soon as possible to indicate whether the picture was taken inside (confounded with alcohol-related content) or outside a building (confounded with neutral content). During instructions, this pairing of location (inside, outside) and content (alcohol, neutral) is not mentioned. An exception to the rule is to be made when an auditory stop signal occurs (NoGo; $25 \%$ of the trials). This stop signal starts with a delay of 100, 200, or $300 \mathrm{~ms}$ (each comprising one third of NoGo trials) after stimulus onset. As this stop signal appears after the picture, and not simultaneously with it, as during the GNG or the training, task performance in the SST depends on action cancellation and thus measures a slightly different aspect of response inhibition. After completion of two practice blocks each, two test blocks comprising 240 trials each (180 Go and 60 NoGo trials) will be completed. The key allocation is counterbalanced, and the order of trials is pseudorandomized. As an indicator of response inhibition, the stop-signal reaction time (SSRT) will be computed for alcohol-related and non-alcoholic pictures according to the algorithm described in Houben, Havermans [32].

\section{Implicit Association Test (IAT)}

Implicit associations between alcohol and affective attributes will be measured with an alcohol-specific IAT [91]. In a valence IAT, pictures of alcoholic beverages are either paired with a positive (e.g., funny) or a negative (e.g., dull) word. Participants must classify if a stimulus either belongs to one of the target categories (pictures of alcoholic drinks vs. waters) or to one of the affective categories (positive vs. negative verbs) with response buttons on a keyboard (left "a" vs. right "l"). The eight alcoholic and eight water pictures are the same as in the inhibition training (see "Stimulus material"). In accordance with previous preclinical studies [32, 33], the affective categories 
consist of eight positive (happy, jolly, energetic, funny, sociable, attractive, cheerful, smart) and eight negative (dull, miserable, sick, depressed, unhappy, disgusting, angry, foolish) attributes. The German translation (glücklich, ausgelassen, dynamisch, lustig, gesellig, attraktiv, fröhlich, klug, lustlos, miserabel, übel, deprimiert, unglücklich, widerlich, wütend, dumm) were validated by three independent native-English speakers. During "alcohol-positive" blocks, stimuli from the categories alcohol and positive are represented by one response button, while water and negative attributes require pressing the other response button. Contrary to this, during "alcohol-negative" blocks, stimuli from the alcohol and negative category share one response button, while water and positive attributes are indicated with the other response button. Based on the rationale that associated concepts (e.g., alcohol and positive attributes) are more easily combined than unrelated concepts (e.g., alcohol and negative attributes), reaction time differences between these two blocks can be used to assess the association strength between target and affective categories. According to the developers [91], a significant difference in reaction time between both examples would indicate strong positive associations towards alcohol.

For this study, task development in E-Prime was based on an adapted version used by Egenolf et al. [92]. To control for sequence effects of the starting target concepts (alcohol, water) both IAT versions consist of 14 blocks. All blocks are interposed with rest periods of a self-determined length. Initially, and whenever key assignment changes, participants will undergo two or three practice blocks consisting of 16 trials each: First, they classify the target concepts (alcohol, water) and/or the affective categories (positive, negative) to left ("a") and right ("l"). Second, they practice the combination of target concepts and affective categories. After these blocks, a longer test block of 64 trials follows (for an overview of the procedure, see Additional file 3). To remind participants of the current mapping rule, category labels will be presented in the upper two corners of the screen. Stimuli will appear on-screen for maximum $1750 \mathrm{~ms}$ or until an answer is given, followed by feedback (for $200 \mathrm{~ms}$ ). The interstimulus interval will be $250 \mathrm{~ms}$. The IAT consists of 416 trials and lasts $10-20$ min depending on the individual's speed and duration of rest periods. Reaction time analyses will be conducted according to the improved scoring algorithm by Greenwald, Nosek et al. [93].

\section{Procedure patients}

The study duration from the admission of the first participant to the last participant's follow-up is $36-40$ months. The duration of participation for an individual study participant is commonly 14-16 months depending on the duration of the inpatient stay. Apart from the main study, the substudies cortisol and EEG are integrated in the main study procedure. During the standard inpatient treatment, the assessments T1 to T4 will take place. After discharge, and at each of the three follow-up time points, questionnaires will be sent to each participant, and they are additionally contacted by telephone (see also Fig. 1). For an overview about the single time points, consult the Standard Protocol Items: Recommendations for International Trials (SPIRIT) Figure (Fig. 2). The SPIRIT Checklist is also provided as Additional file 4.

\section{Recruitment}

At treatment admission, all patients' medical records will be screened for eligibility for participation in the study. If all inclusion criteria and no apparent exclusion criteria are fulfilled, the patient will be invited to an information appointment during the first treatment week. Therein, the study will be explained, questions will be answered, and lastly, the person is asked if they would participate. For those having given informed consent, we will screen for other severe substance use disorders using the DUDIT [47].

\section{T1: Inclusion and baseline assessment}

During the second treatment week, a member of the study team will conduct an interview to confirm the AUD diagnosis (DIA-X adapted to DSM-5 criteria; [55]). To assess the drinking quantity of the 90 days prior to detoxification, the TLFB interview will be conducted [59, 60]. Furthermore, a psychological assessment with a test battery consisting of questionnaires will also take place at this time point.

\section{Randomization and blinding}

Patients will be randomly assigned to one of the three study arms, with the aim of generating equally sized groups. Block randomization with variable block sizes will be stratified according to gender and age (age groups: 18 $25,26-35,36-45,46-55$ and $56-60$ years). The stratified randomization list will be generated with Matlab (Version 2017a, MathWorks, Inc., Natick, MA, USA), and stored in one document. The participants' allocation to a study arm will be done by an independent investigator who will administrate and conceal the list. Thus participants, investigators, care providers and members of the study team will be blind to the allocation schedule.

\section{T2: Pre-training assessment}

Prior to the training, all subjects will undergo an assessment including a series of questionnaires as well as experimental tests measuring implicit associations towards alcohol (IAT) and inhibitory control (GNG, SST). This will take place at the end of the third treatment week. A total of 60 patients (for the EEG substudy) will additionally be assessed with multi-channel EEG while completing the experimental tasks. As the intense confrontation with 


\begin{tabular}{|c|c|c|c|c|c|c|c|c|c|c|}
\hline \multirow[b]{3}{*}{ TIMEPOINTS } & \multicolumn{10}{|c|}{ STUDY PERIOD } \\
\hline & \multirow{2}{*}{$\begin{array}{c}\text { Enrolment } \\
-T 1\end{array}$} & \multirow{2}{*}{$\frac{\text { Allocation }}{0}$} & \multicolumn{5}{|c|}{ Post-allocation } & \multicolumn{3}{|c|}{ Follow-up } \\
\hline & & & $T 1$ & $T 2$ & IT & $T 3$ & $T 4$ & $T 5$ & $T 6$ & $T 7$ \\
\hline $\begin{array}{l}\text { Weeks relative to treatment } \\
\text { entry }\end{array}$ & 1 & 1 & 2 & 3 & 4,5 & 5 & $\begin{array}{l}\tilde{c}^{8-} \\
12+\end{array}$ & $\begin{array}{c}\mathrm{T} 4 \\
+12\end{array}$ & $\begin{array}{c}\mathrm{T} 4 \\
+24\end{array}$ & $\begin{array}{r}\mathrm{T} 4 \\
+52\end{array}$ \\
\hline \multicolumn{11}{|l|}{ ENROLMENT: } \\
\hline Eligibility screen & $\mathrm{x}$ & & & & & & & & & \\
\hline Informed consent & $\mathrm{x}$ & & & & & & & & & \\
\hline Randomization & & $x$ & & & & & & & & \\
\hline \multicolumn{11}{|l|}{ INTERVENTIONS: } \\
\hline Alc-IT (50/50) & & & & & $x$ & & & & & \\
\hline Alc-IT (75/25) & & & & & $x$ & & & & & \\
\hline Control Training & & & & & $x$ & & & & & \\
\hline \multicolumn{11}{|l|}{ EXPERIMENTAL TASKS: } \\
\hline IAT & & & & $x$ & & $x$ & & & & \\
\hline GNG & & & & $\mathrm{x}$ & & $x$ & & & & \\
\hline SST & & & & $\mathrm{x}$ & & $\mathrm{x}$ & & & & \\
\hline \multicolumn{11}{|l|}{ ASSESSMENTS: } \\
\hline Demographics & & & $x$ & & & & & $x$ & $x$ & $x$ \\
\hline \multicolumn{11}{|l|}{$\begin{array}{l}\text { Diagnostics } \\
\text { DIA-X }\end{array}$} \\
\hline \multicolumn{11}{|l|}{$\begin{array}{l}\text { AUD, Psychopathology } \\
\text { AUDIT, BAI, BDI-II, PSS, } \\
\text { SCI }\end{array}$} \\
\hline TLFB & & & $x$ & & & & & $x$ & & \\
\hline $\begin{array}{l}\text { AUD-S, HDL, BSCL, } \\
\text { WHOQOL-BREF }\end{array}$ & & & $\mathrm{x}$ & & & & $\mathrm{x}$ & $\mathrm{x}$ & $\mathrm{x}$ & $\mathrm{x}$ \\
\hline $\begin{array}{l}\text { Alc-related constructs } \\
\text { OCDS-G, AASE-G, } \\
\text { SOCRATES, Craving, } \\
\text { Motivation, CAEQ }\end{array}$ & & & $\mathrm{x}$ & $\mathrm{x}$ & & $\mathrm{x}$ & $x$ & $\mathrm{x}$ & $x$ & $x$ \\
\hline Drinking Goals & & & $x$ & & & & $x$ & $x$ & $x$ & $x$ \\
\hline \multicolumn{11}{|l|}{$\begin{array}{l}\text { Traits } \\
\text { I-8, NISS, ASRS-V1.1, } \\
\text { ASPD, BIS / BAS }\end{array}$} \\
\hline Discharge questionnaire & & & & & & & $x$ & & & \\
\hline $\begin{array}{l}\text { Other } \\
\text { TMT }\end{array}$ & & & $\mathrm{x}$ & & & & & & & \\
\hline Emo-Check & & & $x$ & & & & $x$ & & & \\
\hline
\end{tabular}

Fig. 2 Enrollment, interventions and assessments at each time point for patients in the INTRA study. A schematic outline of the enrollment, interventions and assessments that each participant of the main INTRA study will undergo. AASE-G Alcohol Abstinence Self-efficacy Scale German version, Alc-IT alcohol-inhibition training, ASPD antisocial personality disorder, ASRS-V1.1 Adult ADHD Self-Report Scale, AUDIT Alcohol Use Disorders Identification Test, AUD-S Alcohol Use Disorders Scale, BAI Beck Anxiety Inventory, BDI-II Beck's Depression Inventory, BIS/BAS Behavioral Inhibition System/Behavioral Approach System Scale, BSCL Brief Symptom Check List, CAEQ Comprehensive Alcohol Expectancy Questionnaire; Craving (Likert scales), DIA-X Diagnostic Expert System for Psychiatric Disorders, Emo-Check Assessment of Emotion and Emotion regulation, GNG Go-NoGo Task, HDL Health and Daily Living Form, IAT Implicit Association Test, IT inhibition training, I-8 Scale for Impulsive Behavior, Motivation (Likert scales), NISS Need Inventory of Sensation Seeking, OCDS-G Obsessive Compulsive Drinking Scale - German version, PSS PTSD Symptom Scale, SCI StresS and Coping Inventory, SOCRATES Stages of Change Readiness and Treatment Eagerness Scale, SST Stop-Signal Task, TLFB Timeline Follow-back, TMT Trail Making Test A and B, WHOQOL-BREF WHO Quality of Life Scale (brief version), -T1 before treatment admission, T1 baseline, T2 pre-training, T3 post training, T4 discharge, T5 3-month follow-up, T6 6-month follow-up, T7 12-month follow-up

alcohol pictures may lead to tension and induce craving in patients with AUD, we will monitor our participants' stress and craving on an 11-point Likert scale $(0=$ not at all, $10=$ very strong) immediately before and after the assessment. In the case of significant stress or craving levels, the medical staff on duty will be contacted and informed. 


\section{Training (intervention)}

During weeks 4 and 5 of the treatment, all patients will undergo six short training sessions according to their allocated training version (Alc-IT (75/25), Alc-IT (50/50) or control group, either in the morning or afternoon). All training sessions will be distributed over 2 weeks, performed in a group setting, and monitored by a member of the study team. At the beginning of the first session, participants undergo a short practice version to confirm that they understood the task. Before and after each training session, stress and craving will be assessed (see also T2). At the end of each training session, the study member will take note of the participants' reaction time and error rate, with the aim to maintain motivation. In order to assess saliva cortisol concentration for the cortisol substudy, saliva samples of 80 patients of the Suedhang Hospital will be collected before and after the first training.

\section{T3: Post-training assessment}

One to 4 days after the last training session, patients will undergo the same assessment as in T2 (including questionnaires and experimental tasks). The 60 participants of the EEG substudy again participate in the EEG recording during the experimental tasks. Before and after the measurement, self-reported stress and craving will be assessed (see also T2).

\section{Discharge assessment (T4)}

Upon discharge from inpatient treatment, psychological parameters are measured again with the questionnaires used at previous time points. At the end of T4, the procedure for the follow-up measurements will be explained.

\section{3-month follow-up (T5)}

Three months after discharge, all participants will be contacted by telephone. The primary outcome variables will be assessed in a short telephone interview, and an appointment for the TLFB interview will be arranged if it cannot be carried out at the time of the call. Parallel to this telephone interview, a questionnaire battery will be sent to the patients' private address.

\section{6- and 12-month follow-up (T6, T7)}

Six (T6) and 12 (T7) months after discharge, a similar procedure as in $\mathrm{T} 5$ will be performed. At both time points, participants will receive the questionnaire battery by post and will be called by telephone to assess the most significant outcome variables.

\section{Procedure to enhance response rates at the follow-up assessments (T5, T6, T7)}

To achieve high response rates, a meticulous plan will be pursued for each follow-up assessment: Participants will be contacted by telephone starting 10 days prior to the target day (90, 180 and 365 days after discharge) to announce the upcoming assessment. Should three contact attempts fail, a text message is sent. In case of no response, they are called another seven times, and a set of questionnaires will be sent shortly before the target day. If these questionnaires are not returned within 15 days, they are called another 10 times. If provided, an additional email is sent. This procedure will be repeated if the patient has been reached yet no questionnaires are returned. If it is possible to talk to the participant at any time during the process, the most important primary outcome variables are queried. This entails that at least the most important variables can be collected, even if the participant does not return the questionnaires. As a last resort, a voluntarily provided contact of the participant is called. If none of these attempts succeed, the follow-up assessment will be terminated. Participants receive $20 \mathrm{CHF}$ for each follow-up assessment.

\section{Procedure for substudies Cortisol substudy}

Inclusion and exclusion criteria for the substudy match those of the main study. The first 80 patients who are recruited in the Suedhang Hospital will be additionally asked to participate in the cortisol substudy, which involves collecting a salvia-cortisol sample before and after the first training session.

\section{EEG substudy}

As this involves more time-consuming measurements at T2 and T3, a two-level recruitment-process will be implemented: Inclusion and exclusion criteria for the substudy match those of the main study. However, recruitment of these participants will additionally depend on their mental capacity, age and gender balance, and their available time considering the clinic's already demanding agenda. If eligible patients are interested in participating, additional information concerning EEG measurements will be provided, and an additional informed consent for this substudy will be signed. When 20 participants per training version are included in this substudy, the recruitment procedure will be stopped. Patients enrolled in the EEG substudy will receive a monetary compensation of $50 \mathrm{CHF}$ per measurement.

\section{Procedure for healthy controls}

Interested potential participants will receive the participant's information and informed consent to read. If eligible for the study, a member of the study team will verify the inclusion and exclusion criteria during a screening. If a person is included in the study, written informed consent will be obtained, and the subject will undergo the same experimental tasks (IAT, GNG, SST) and a similar 
questionnaire battery as the patient sample at T1 (for an overview, see Additional file 5). Questionnaires and behavioral data during tasks will be collected from 30 healthy controls, the same measurement will be collected from another 20 additional healthy controls while an EEG is recorded during the experimental tasks (T2 and T3). Healthy controls without an EEG will receive no monetary compensation, whereas subjects in the EEG group will receive $30 \mathrm{CHF}$ for any EEG-related inconvenience.

\section{Data collection and statistical analysis Questionnaires}

Will be assessed by using paper and pencil and will then be entered into SPSS (Version 24.0, IBM SPSS Statistics for Windows, IBM Corp, Armonk, NY, USA). Behavioral data will be collected with E-Prime 2.0 (EP2Pro2.0.10.356, Psychology Software Tools, Inc., Sharpsburg, PA, USA).

\section{EEG data}

Electrophysiological data will be recorded with BrainVision Recorder (Version 2.0, Brain Products GmbH, Gilching, Germany) using 64 active electrodes distributed across the scalp according to the extended 10/10 system. The sampling rate is $500 \mathrm{~Hz}$, online filters are set to $0.016 \mathrm{~Hz}$ (highpass) and $250 \mathrm{~Hz}$ (low pass), impedances are kept below 20 $\mathrm{k} \Omega, \mathrm{FCz}$ will serve as on-line reference. Each participant will first undergo a 5-min resting state EEG with alternating epochs of eyes open and eyes closed. Then, the experimental test battery of the T2 and T3 assessment, consisting of a Go-NoGo Task (GNG), an Implicit Association Test (IAT) and a Stop-Signal Task (SST), will be administered while the EEG is still recorded. For details about the tasks, please see section "Experimental tasks."

\section{Cortisol data}

Saliva samples for cortisol analyses will be stored at $-80^{\circ} \mathrm{C}$.

\section{Statistics}

All statistical analyses will be conducted by the members of the study team. The main analyses of the training effect will be carried out after data collection is completed to maintain the study's double-blind design. All behavioral and questionnaire variables will be tested for normal distribution (Kolmogorov-Smirnov test: $p>0.1$, for all variables)

\section{Main study}

Training effects on our primary outcome measures (PDA and HDD at 3-month follow-up) will be assessed with a $2 \times 3$ analysis of variance (ANOVA) with the factors time point (T1, T5) and training group (Alc-IT (50/ 50), Alc-IT (75/25) or control). Further, a Cox regression will be computed to predict the effect of the intervention on TFD (at 3-month follow-up).
Training effects on experimental test parameters will be assessed with a $2 \times 2 \times 3$ repeated measures ANOVA with the factors measurement point (T2, T3), time of day (morning, afternoon) and training group (Alc-IT (50/50), Alc-IT (75/25) or control). Where Mauchly's test of sphericity indicates heterogeneity of covariance, we will verify repeated measures results with Greenhouse-Geisser corrections.

\section{EEG substudy}

All raw EEG data will be pre-processed with BrainVision Analyzer (Version 2.0, Brain Products GmbH, Gilching, Germany) according to current standards including ICAbased correction of eye-movement artefacts, artefact rejection and application of band-pass filtering (see e.g., [9496]). Event-related potentials (ERPs) will be computed for each stimulus type in the three experiments (IAT, GNG, SST). Epochs from $500 \mathrm{~ms}$ (pre-stimulus) to $1500 \mathrm{~ms}$ (post-stimulus) will be averaged separately for each stimulus type and measurement point (T2 and T3). ERPs will subsequently be statistically compared for overall amplitude (i.e., global field power, GFP) and topography. For each ERP, GFP [97] will be calculated as the standard deviation across electrodes, thus measuring momentary global signal strength regardless of topographic modulations. GFP values for each point in time will be extracted and compared (T2 vs. T3) with nonparametric randomization tests, which simultaneously control for multiple comparisons. The analyses will be conducted using the Ragu software $[98,99]$.

To inspect for topographic differences between ERPs measured before and after the training, a topographic analysis of variance (TANOVA) [100] will be computed in Ragu. Here, dissimilarities of electric field topographies are identified with a nonparametric randomization test. A significant finding in the TANOVA indicates that activation in underlying brain structures vary in relation to the factor under investigation. Significant TANOVA results will be further explored with the standardized low-resolution electromagnetic tomography (sLORETA) source analysis method [101]) to determine which brain regions vary in activation in relation to stimulus type and/or measurement time (T2 vs. T3).

Based on prior findings, our ERP analyses will focus on the timeframe from about 150 to about $850 \mathrm{~ms}$. Exact timeframes will be defined based on components as visible in GFP-curves or by microstate analyses [102, 103]. Following earlier research, care will be taken to include the N2 and P3 components in case of the GNG [25, 26] and the N2, P3, N4 and LPP components in case of the IAT (e.g., [104-106]).

\section{Cortisol substudy}

Salivary cortisol concentrations are determined by a commercially available chemiluminescence immunoassay 
(CLIA; IBL, Hamburg, Germany). Inter- and intra-assay coefficients of variation are both below 8\%. For biochemical analyses of free cortisol concentration, saliva samples will be thawed and spun at $3000 \mathrm{rpm}$ for $10 \mathrm{~min}$ to obtain $0.5-1.0 \mathrm{ml}$ of clear saliva with low viscosity.

\section{Power calculation}

The intended sample size was calculated with G*Power (Version 3.1.5, Heinrich-Heine-University Duesseldorf, Dusseldorf, Germany). In a-priori analyses $(1-\beta=0.8$, $\alpha=0.05$ ), slightly reduced expected effect sizes were entered compared to earlier studies because of the additional manipulations concerning different training versions and time of training. For the $2 \times 3$ ANOVA to examine the training effects on the primary outcome measures PDA and HDD (with an expected effect size of $\mathrm{f}=0.2$ based on earlier studies [32]), a total sample size of $n=244$ is needed. For the analyses of the training's effect on TFD (the third primary outcome, estimating a small to medium effect size of $\mathrm{w}=0.25$ based on earlier studies [37], and $\mathrm{df}=3$ ), $\mathrm{G}^{*}$ Power indicated a total sample size of $n=174$ for the Cox regression. For the $2 \times$ $2 \times 3$ repeated measures ANOVA examining training effects on experimental parameters and also taking into account the effects of time of day of the training (expecting small to medium effects of $\mathrm{f}=0.15$ and correlations of 0.4 among repeated measures based on earlier studies [107]), the necessary sample size was $n=180$. Considering the necessary power for all analyses and similar sample sizes in all study arms (82 per intervention group), a total of 246 patients will be recruited.

\section{Discussion}

The results of the INTRA study should provide evidence for the efficacy of an add-on treatment to specialized standard care for AUD. In contrast to previous nonclinical studies [32, 33], this double-blind RCT investigates the effect of a computerized inhibition training in inpatients with AUD. It includes important measures of alcohol consumption and follow-up periods of up to 1 year. With respect to working mechanisms, the study includes a thorough assessment of inhibitory control functions and alcohol-specific implicit associations on both a behavioral and neurophysiological level. Through this investigation, we hope to expand current knowledge about the role of inhibitory functions in AUD and extend previous findings about the effects of this training [25, 26, $32-37]$. In order to describe the patients' baseline measures, including possible inhibitory deficits, and to better interpret the observed modifications, the patients' behavioral and neurophysiological data will be compared to healthy controls.

In additional to these proximal findings, the effect of the intervention will also be analyzed longitudinally. At
3-, 6- and 12-month follow-ups, important measures of alcohol consumption, our primary outcome, as well as psychological parameters will be collected to inform us about the time after inpatient treatment. Finally, this trial will investigate whether endogenous cortisol might increase possible effects of the inhibition training.

As one potential limitation, one could argue that patients in the control training group undergo a noncontext-specific inhibition training, which might enhance their general inhibitory capacities. The choice of the control group is, therefore, very strict and could lead to an underestimation of the effect of the inhibition training. However, control conditions used in previous non-clinical studies $[32,33]$ consistently paired alcohol stimuli with Go responses and tended to enhance alcohol consumption in these samples. Therefore, due to ethical considerations, we opted against this control condition in a clinical sample.

Overall, the current double-blind RCT is the first study to investigate the effect of an inhibition training in an inpatient treatment setting in patients with AUD. It allows a detailed proximal and distal evaluation of behavioral, psychological and neurophysiological processes in AUD and of the efficacy of the inhibition training. We therefore hope that it might ultimately contribute to the improvement of evidenced-based AUD treatment.

\section{Trial status}

The trial is currently in the data collection phase, which is planned to end in March 2020.

\section{Additional files}

Additional file 1: Inclusion/exclusion criteria for all participants. (PDF $21 \mathrm{~kb}$ )

Additional file 2: Representative pictures of the five stimulus sets. (PDF $126 \mathrm{~kb}$ )

Additional file 3: Overview of Implicit Association Test (IAT) blocks for both versions. (PDF $90 \mathrm{~kb}$ )

Additional file 4: Standard Protocol Items: Recommendations for International Trials (SPIRIT) Checklist. (PDF $191 \mathrm{~kb}$ )

Additional file 5: Overview of measures for healthy controls. (PDF $18 \mathrm{~kb}$ )

\footnotetext{
Abbreviations

AASE-G: Alcohol Abstinence Self-Efficacy Scale - German version; Alc-IT: Alcohol-inhibition training; ANOVA: Analysis of variance; ASPD: Antisocial personality disorder; ASRS-V1.1: ADHD Self Report Scale; AUD: Alcohol use disorder; AUDIT: Alcohol Use Disorders Identification Test; AUD-S: Alcohol Use Disorder Scale; BAI: Beck Anxiety Inventory; BDI-II: Beck Depression Inventory (Version 2); BIS/BAS: Behavioral Inhibition System/Behavioral Approach System Scales; BSCL: Brief Symptom Check List;

CAEQ: Comprehensive Alcohol Expectancy Scale; DIA-X: Diagnostic Expert System for Psychiatric Disorders; DSM-5: Diagnostic and Statistical Manual of Mental Disorders (Version 5); DSM-IV: Diagnostic and Statistical Manual of Mental Disorders (Version 4); DUDIT: Drug Use Identification Test;

EEG: Electroencephalography; EOC: Errors of commission; ERP: Event-related potential; GFP: Gobal field power; GNG: Go-NoGo Task; HDD: Heavy-drinking day; HDL: Health and Daily Living Form; I-8: Scale for Impulsive Behavior;
} 
IAT: Implicit Association Test; INTRA: Inhibition training; OCDS-G: Obsessive Compulsive Drinking Scale - German version; PDA: Percentage of days abstinent; PSS: PTSD Screening Scale; SCl: Stress and Coping Inventory; SD: Standard drink; SLORETA: Standardized low-resolution electromagnetic tomography; SOCRATES: Change Readiness and Treatment Eagerness Scale; SPIRIT: Standard Protocol Items: Recommendations for International Trials; SSRT: Stop-signal reaction time; SST: Stop-Signal Task; SUD: Substance use disorder; TANOVA: Topographic analysis of variance; TFD: Time to first drink; TLFB: Timeline Follow-back; TMT: Trail Making Test; WHO: World Health Organization; WHOQOL-BREF: World Health Organization Quality of Life (brief version)

\section{Acknowledgements}

The authors would like to thank Katrijn Houben and her co-authors for providing their version of the inhibition training and Yvonne Egenolf and her co-authors for providing access to their IAT version. We further thank Sonja Kaufmann, Nora Schoenenberger, Brigitta Ryter, Luzius Pfiffner, Mirela Dubravnac and Sarah Diezig for their excellent research assistance and support.

\section{Authors' contributions}

RT and MS wrote the first version of the manuscript. The design, development, supervision and organization of funding of this study as well as the analytic strategy were devised by MS, LS and FM. HB and RT are responsible for the organization of data collection and the implementation of the study at the three study sites. The organization of data collection for both substudies with healthy controls (behavioral and EEG) was implemented by MS, RT and HB. All authors supported the writing process, read and approved the final manuscript.

\section{Funding}

Funding of this trial was provided by a grant from the Swiss National Foundation in 2015 (SNF; No: 105319_159286, "Learning to resist the urge: Inhibition training in abstinent alcohol dependent patients"/ CHF 200'999) given to MS, LS and FM. The funding bodies have no influence on the design, the analysis and interpretation of the trial, nor in the preparation or approval of the manuscript.

\section{Availability of data and materials}

Not applicable as the current manuscript does not contain data.

\section{Ethics approval and consent to participate}

Central and local ethical approval has been confirmed from the Ethics Committee of Bern, Switzerland, in cooperation with the Ethics Committee of Zürich, Switzerland (combined ref. approval no. 2016-00988). All participants give written informed consent, which they can revoke at any time of the trial.

\section{Consent for publication}

All participants gave their consent for publication within their informed consent.

\section{Competing interests}

The authors declare that they have no competing interests.

\section{Author details}

'Translational Research Center, University Hospital of Psychiatry, University of Bern, Bern, Switzerland. ${ }^{2}$ Center for Treatment of Addictive Disorders, Clinic Suedhang, Kirchlindach, Switzerland. ${ }^{3}$ Department of Clinical Psychology and Psychotherapy, Institute of Psychology, University of Bern, Bern, Switzerland.

Received: 20 November 2018 Accepted: 10 June 2019

Published online: 05 July 2019

\section{References}

1. Rehm J. The risks associated with alcohol use and alcoholism. Alcohol Res Health. 2011;34:135-43.

2. Rehm J, Mathers C, Popova S, Thavorncharoensap M, Teerawattananon Y, Patra J. Global burden of disease and injury and economic cost attributable to alcohol use and alcohol-use disorders. Lancet. 2009;373:2223-33.

3. Nutt DJ, King LA, Phillips LD. Drug harms in the UK: a multicriteria decision analysis. Lancet. 2010;376:1558-65.
4. Morgan CJ, Muetzelfeldt L, Muetzelfeldt M, Nutt DJ, Curran HV. Harms associated with psychoactive substances: findings of the UK National Drug Survey. J Psychopharmacol. 2010;24:147-53.

5. McKay JR. Is there a case for extended interventions for alcohol and drug use disorders? Addiction. 2005;100:1594-610.

6. McLellan AT, Lewis DC, O'Brien CP, Kleber HD. Drug dependence, a chronic medical illness implications for treatment, insurance, and outcomes evaluation. JAMA. 2000;284:1689-95.

7. O'Brien C. A.T M. Myths about the treatment of addiction. Lancet. 1996; 347:237-40.

8. Miller WR, Andrews NR, Wilbourne P, Bennett ME. A wealth of alternatives: effective treatments for alcohol problems. In: Miller WR, Heather N, editors. Applied clinical psychology. Treating addictive behaviors. New York: Plenum Press; 1998. p. 203-16.

9. Mann K, Hermann D. Individualised treatment in alcohol-dependent patients. Eur Arch Psychiatry Clin Neurosci. 2010;260(Suppl 2):S116-20.

10. Robinson TE, Berridge KC. The neural basis of drug craving: an incentivesensitization theory of addiction. Brain Res Rev. 1993;18:247-91.

11. Kalivas PW, Volkow ND. The neural basis of addiction: a pathology of motivation and choice. Am J Psychiatry. 2005;162:1403-13.

12. Schultz W, Tremblay L, Hollerman JR. Reward processing in primate orbitofrontal cortex and basal ganglia. Cereb Cortex. 2000;20:272-83.

13. Wiers RW, Teachman BA, De Houwer J. Implicit cognitive processes in psychopathology: an introduction. J Behav Ther Exp Psychiatry. 2007:38:95-104.

14. Volkow ND, Li T-K. Drug addiction: the neurobiology of behaviour gone awry. Nat Rev Neurosci. 2004;5:963-70.

15. Wiers RW, Bartholow BD, van den Wildenberg E, Thush C, Engels RC, Sher $\mathrm{KJ}$, et al. Automatic and controlled processes and the development of addictive behaviors in adolescents: a review and a model. Pharmacol Biochem Behav. 2007:86:263-83.

16. Wiers RW, Gladwin TE, Hofmann W, Salemink E, Ridderinkhof KR. Cognitive bias modification and cognitive control training in addiction and related psychopathology. Clin Psychol Sci. 2013;1:192-212.

17. Volkow ND, Baler RD. Addiction science: uncovering neurobiological complexity. Neuropharmacology. 2014;76:235-349.

18. Schacht JP, Anton RF, Myrick H. Functional neuroimaging studies of alcohol cue reactivity: a quantitative meta-analysis and systematic review. Addict Biol. 2013;18:121-33.

19. Fillmore MT. Drug abuse as a problem of impaired control: current approaches and findings. Behav Cogn Neu Rev. 2003;2:179-97.

20. Fillmore MT, Rush CR. Impaired inhibitory control of behavior in chronic cocaine users. Drug Alcohol Depend. 2002;66:265-73.

21. Lubman DI, Yucel M, Pantelis C. Addiction, a condition of compulsive behaviour? Neuroimaging and neuropsychological evidence of inhibitory dysregulation. Addiction. 2004;99:1491-502.

22. Garavan $\mathrm{H}$, Hester R. The role of cognitive control in cocaine dependence. Neuropsychol Rev. 2007;17:337-45

23. Kaufman JN, Ross TJ, Stein EA, Garavan H. Cingulate hypoactivity in cocaine users during a go-nogo task as revealed by event-related functional magnetic resonance imaging. J Neurosci. 2003;23:7839-43.

24. Hester R, Garavan H. Executive dysfunction in cocaine addiction: evidence for discordant frontal, cingulate, and cerebellar activity. J Neurosci. 2004;24:11017-22.

25. Stein M, Fey W, Koenig T, Oehy J, Moggi F. Context-specific inhibition is related to craving in alcohol use disorders: a dangerous imbalance. Alcohol Clin Exp Res. 2018;42:69-80.

26. Petit G, Kornreich C, Noel X, Verbanck P, Campanella S. Alcohol-related context modulates performance of social drinkers in a visual Go/No-Go task: a preliminary assessment of event-related potentials. PLoS One. 2012;7:e37466.

27. Ames SL, Wong SW, Bechara A, Cappelli C, Dust M, Grenard JL, et al. Neural correlates of a Go/NoGo task with alcohol stimuli in light and heavy young drinkers. Behav Brain Res. 2014;274:382-9.

28. Czapla M, Baeuchl C, Simon JJ, Richter B, Kluge M, Friederich HC, et al. Do alcohol-dependent patients show different neural activation during response inhibition than healthy controls in an alcohol-related fMRI go/nogo-task? Psychopharmacology. 2017;234:1001-15.

29. Veling $\mathrm{H}$, Aarts $\mathrm{H}$. Unintentional preparation of motor impulses after incidental perception of need-rewarding objects. Cogn Emot. 2011;25:1131-8.

30. Veling $H$, Aarts $H$, Papies EK. Using stop signals to inhibit chronic dieters' responses toward palatable foods. Behav Res Ther. 2011;49:771-80. 
31. Veling $\mathrm{H}$, Aarts $\mathrm{H}$, Stroebe W. Stop signals decrease choices for palatable foods through decreased food evaluation. Front Psychol. 2013;4:875.

32. Houben K, Havermans RC, Nederkoorn C, Jansen A. Beer a no-go: learning to stop responding to alcohol cues reduces alcohol intake via reduced affective associations rather than increased response inhibition. Addiction. 2012;107:1280-7.

33. Houben K, Nederkoorn C, Wiers RW, Jansen A. Resisting temptation: decreasing alcohol-related affect and drinking behavior by training response inhibition. Drug Alcohol Depend. 2011;116:132-6.

34. Smith JL, Dash NJ, Johnstone SJ, Houben K, Field M. Current forms of inhibitory training produce no greater reduction in drinking than simple assessment: a preliminary study. Drug Alcohol Depend. 2017;173:47-58.

35. Bowley C, Faricy C, Hegarty B, Johnstone SJ, Smith JL, Kelly JP, et al. The effects of inhibitory control training on alcohol consumption, implicit alcohol-related cognitions and brain electrical activity. Int J Psychophysiol. 2013;89:342-8.

36. Di Lemma LCG, Field M. Cue avoidance training and inhibitory control training for the reduction of alcohol consumption: a comparison of effectiveness and investigation of their mechanisms of action. Psychopharmacology. 2017;234:2489-98.

37. Kilwein TM, Bernhardt KA, Stryker ML, Looby A. Decreased alcohol consumption after pairing alcohol-related cues with an inhibitory response. J Subst Use. 2017;23:154-61.

38. Veling $\mathrm{H}, \mathrm{Holland} \mathrm{RW}$, van Knippenberg A. When approach motivation and behavioral inhibition collide: behavior regulation through stimulus devaluation. J Exp Soc Psychol. 2008:44:1013-9.

39. Smith JL, Johnstone SJ, Barry RJ. Response priming in the Go/NoGo task: the N2 reflects neither inhibition nor conflict. Clin Neurophysiol. 2007;118:343-55.

40. Demmel R, Hagen J. The comprehensive alcohol expectancy questionnaire: II. Prediction of alcohol use and clinical utility. SUCHT. 2003;49:300-5.

41. Ludwig F, Tadayon-Manssuri E, Strik W, Moggi F. Self-efficacy as a predictor of outcome after residential treatment programs for alcohol dependence: simply ask the patient one question! Alcohol Clin Exp Res. 2013:37:663-7.

42. Bauer S, Strik W, Moggi F. Motivation as a predictor of drinking outcomes after residential treatment programs for alcohol dependence. J Addict Med. 2014;8:137-42.

43. Wapp M, Burren Y, Znoj H, Moggi F. Association of alcohol craving and proximal outcomes of a residential treatment program for patients with alcohol use disorders. J Subst Use. 2015;20:11-5.

44. Lass-Hennemann J, Michael T. Endogenous cortisol levels influence exposure therapy in spider phobia. Behav Res Ther. 2014;60:39-45.

45. Kirschbaum C, Hellhammer DH. Salivary cortisol in psychobiological research: an overview. Neuropsychobiology. 1989;22:150-69.

46. Soravia LM, Heinrichs M, Winzeler L, Fisler M, Schmitt W, Horn H, et al. Glucocorticoids enhance in vivo exposure-based therapy of spider phobia. Depress Anxiety. 2014;31:429-35.

47. Berman AH, Bergman H, Palmstierna T, Schlyter F. Evaluation of the Drug Use Disorders Identification Test (DUDIT) in criminal justice and detoxification settings and in a swedish population sample. Eur Addict Res. 2005;11:22-31.

48. Voluse AC, Gioia CJ, Sobell LC, Dum M, Sobell MB, Simco ER. Psychometric properties of the Drug Use Disorders Identification Test (DUDIT) with substance abusers in outpatient and residential treatment. Addict Behav. 2012; 37:36-41.

49. Babor TF, Higgins-Biddle JC, Saunders JB, Monteiro MG. The Alcohol Use Disorders Identification Test. guidelines for use in primary care. Geneva: World Health Organization; 2001.

50. Wechsler H, Davenport A, Dowdall G, Moeykens B, Castillo S. Health and behavioral consequences of binge drinking in college. A national survey of students at 140 campuses. JAMA. 1994;272:1672-7.

51. Derogatis LR. Brief Symptom Inventory: administration, scoring, and procedures manual. Minneapolis: MN, National Computer Systems; 1993.

52. Franke GH. Brief Symptom Inventory von L.R. Derogatis-Deutsches Manual. [Brief Symptom Inventory of L.R. Derogatis-German Manual]. Göttingen: Beltz; 2000.

53. Fey W, Moggi F, Rohde KB, Michel C, Seitz A, Stein M. Development of stimulus material for research in alcohol use disorders. Int J Methods Psychiatr Res. 2017;26:e1527.

54. Eberl C, Wiers RW, Pawelczack S, Rinck M, Becker ES, Lindenmeyer J. Implementation of approach bias re-training in alcoholism-how many sessions are needed? Alcohol Clin Exp Res. 2014;38:587-94.

55. Wittchen HU, Pfister $\mathrm{H}$. Instruktionsmanual zur Durchführung von DIA-XInterviews. Frankfurt: Swets Test Services; 1997.
56. Moos RH, Cronkite RH, Finney JW. Health and Daily Living Form Manual. Palo Alto: Mind Garden; 1990.

57. Moggi F, Giovanoli A, Strik W, Moos BS, Moos RH. Substance use disorder treatment programs in Switzerland and the USA: program characteristics and 1-year outcomes. Drug Alcohol Depend. 2007;86:75-83.

58. Moggi F, Giovanoli A, Buri C, Moos BS, Moos RH. Patients with substance use and personality disorders: a comparison of patient characteristics, treatment process, and outcomes in Swiss and U.S. substance use disorder programs. Am J Drug Alcohol Abuse. 2010;36:66-72.

59. Sobell LC, Follow-back SMBT. a technique for assessing self-reported ethanol consumption. In: Allen J, Litten RZ, editors. Measuring alcohol consumption: psychosocial and biological methods. Totowa, NJ: Humana Press ed. Totowa: Humana Press; 1992. p. 41-72.

60. Sobell LC, Sobell MB. Alcohol Timeline Followback users' manual. Toronto: Addiction Research Foundation; 1995.

61. Mann K, Ackermann K. Die OCDS-G: Psychometrische Kennwerte der deutschen Version der Obsessive Compulsive Drinking Scale. SUCHT. 2000;46:90-100

62. Miller WR, Tonnigan JS. Assessing drinker's motivation for change: the Stages of Change Readiness and Treatment Eagerness Scale (SOCRATES). Psychol Addict Behav. 1996;10:81-9.

63. Demmel R. Motivational interviewing. In: Linden M, Hautzinger M, editors. Verhaltenstherapiemanual 8ed. Heidelberg: Springer; 2005. p. 228-33.

64. Miller WR, Rollnick S. Motivierende Gesprächsführung. 2nd ed. Freiburg im Preisgau: Lambertus-Verlag; 2002.

65. Bott KE, Rumpf H-J, Bischof G, Meyer C, Hapke U, John U. AlcoholabstinenzSelbstwirksamkeitsfragebogen; Deutsche Version (AASE-G); deutsche Version der Alcohol abstinence Self-efficacy-Scale, German Version. In: Glöckner-Rist A, Rist F, Küfner H, editors. Elektronisches Handbuch zu Erhebungsinstrumenten im Suchtbereich (EHES). 3rd ed. Mannheim: Zentrum für Umfragen, Methoden und Analysen; 2003.

66. Demmel R, Hagen J. The comprehensive alcohol expectancy questionnaire: I. Scale development. SUCHT. 2003;49:292-9.

67. Nicolai J, Demmel R, Moshagen M. The comprehensive alcohol expectancy questionnaire: confirmatory factor analysis, scale refinement, and further validation. J Pers Assess. 2010:92:400-9.

68. Beck AT, Steer RA. Beck Anxiety Inventory Manual San Antonio The Psychological Corporation; 1993.

69. Margraf J, Ehlers A. BAl: Beck-Angst-Inventar. Manual. Deutsche Bearbeitung. Frankfurt/Main: Harcourt Test Services; 2007.

70. Beck AT, Steer RA, Brown GK. BDI-II Beck Depressions-Inventar 2. Auflage. Frankfurt/Main: Harcourt; 2006.

71. Hautzinger M, Keller F, Kühner C. Beck Depressions-Inventar (BDI-II). Revision. Frankfurt/Main: Harcourt Test Services; 2006.

72. Lauth GW, Minsel W-R. KATE. Kölner ADHS-Test für Erwachsene. Göttingen: Hoegrefe; 2014.

73. Kessler RC, Adler L, Ames M, Demler O, Faraone S, Hiripi EVA, et al. The World Health Organization adult ADHD Self-report Scale (ASRS): a short screening scale for use in the general population. Psychol Med. 2005; 35:245-56.

74. Foa EB, Cashman L, Jaycox L, Perry K. The validation of a self-report measure of posttraumatic stress disorder: The Posttraumatic Diagnostic Scale. Psychol Assess. 1997:9:445-51.

75. Stieglitz E-D, Frommberger U, Foa EB, Berger M. Evaluation of the german version of the PTSD Symptom Scale (PSS). Psychopathology. 2001;34:128-33.

76. Satow L. Stress- und Coping-Inventar (SCI): Test- und Skalendokumentation 2012 [updated 03.07.2018]. Available from: http://www.drsatow.de.

77. Angermeyer MC, Kilian R, Matschinger H. WHOQOL-100 und WHOQOLBREF. Handbuch für die deutschsprachige Version der WHO Instrumente zur Erfassung von Lebensqualität. Göttingen: Hogrefe; 2000.

78. WHOQOL group. Development of the World Health Organization WHOQOLBREF quality of life assessment. Psychol Med. 1998;28:551-8.

79. Kovaleva A, Beierlein C, Kemper CJ, Rammstedt B. Eine Kurzskala zur Messung von Impulsivität nach dem UPPS-Ansatz: Die Skala ImpulsivesVerhalten-8 (I-8). Working Papers. 2012;20:5-31.

80. Roth M, Hammelstein P. The Need Inventory of Sensation Seeking (NISS). EJPA. 2012;28:11-8.

81. Sheehan DV, Lecrubier $Y$, Sheehan KH, Amorim P, Janavs J, Weiller $E$, et al. The Mini-International Neuropsychiatric Interview (M.I.N.I.): the development and validation of a structured diagnostic psychiatric interview for DSM-IV and ICD-10. J Clin Psychiatry. 1998;59:22-33. 
82. Foster S, Held L, Estevez N, Gmel G, Mohler-Kuo M. Liberal alcohol legislation: does it amplify the effects among Swiss men of person-related risk factors on heavy alcohol use? Addiction. 2015;110:1746-56.

83. Carver CS, White TL. Behavioral inhibition, behavioral activation, and affective responses to impending reward and punishment: the BIS/BAS scales. JPSP. 1994:67:319-33.

84. Studer J, Baggio S, Mohler-Kuo M, Daeppen J-B, Gmel G. Factor structure and psychometric properties of a French and German shortened version of the behavioural inhibition system/behavioural activation system scales. Int J Methods Psychiatr Res. 2016:25:44-54.

85. Strobel A, Beauducel A, Debener S, Brocke B. Eine deutschsprachige Version des BIS/BAS-Fragebogens von Carver und White. ZDDP. 2001;22:216-27.

86. Berking M, Wupperman P, Reichardt A, Pejic T, Dippel A, General ZH. emotion-regulation skills as a treatment target in psychotherapy. Behav Res Ther. 2008:46:1230-7.

87. Berking M, Znoj H. Entwicklung und Validierung eines Fragebogens zur standardisierten Selbsteinschätzung emotionaler Kompetenzen (SEK-27). Z Klin Psychol Psychiatr Psychother. 2008:56:141-52.

88. Reitan RM. Trail Making Test. Indianapolis: Indiana University Medical Center; 1959.

89. Houben K, Wiers RW. Response inhibition moderates the relationship between implicit associations and drinking behavior. Alcohol Clin Exp Res. 2009;33:626-33.

90. Peeters $M$, Wiers RW, Monshouwer $K$, van de Schoot $R$, Janssen $T$ Vollebergh WAM. Automatic processes in at-risk adolescents: the role of alcohol-approach tendencies and response inhibition in drinking behavior. Addiction. 2012;107:1939-46.

91. Greenwald AG, McGhee DE, Schwartz JLK. Measuring individual differences in implicit cognition: the Implicit Association Test. JPSP. 1998;74:1464-80.

92. Egenolf $Y$, Stein M, Koenig T, Grosse Holtforth M, Dierks T, Caspar F. Tracking the implicit self using event-related potentials. Cogn Affect Behav Neurosci. 2013;13:885-99.

93. Greenwald AG, Nosek BA, Banaji MR. Understanding and using the Implicit Association Test: I. An improved scoring algorithm. JPSP. 2003;85:197-216.

94. Stein M, Dierks T, Brandeis D, Wirth M, Strik W, Koenig T. Plasticity in the adult language system: a longitudinal electrophysiological study on second language learning. Neuroimage. 2006;33:774-83.

95. Rohde KB, Caspar F, Koenig T, Pascual-Leone A, Stein M. Neurophysiological traces of interpersonal pain: how emotional autobiographical memories affect event-related potentials. Emotion. 2018;18:290-303.

96. Wirth M, Horn H, Koenig T, Razafimandimby A, Stein M, Mueller T, et al. The early context effect reflects activity in the temporo-prefrontal semantic system: evidence from electrical neuroimaging of abstract and concrete word reading. Neuroimage. 2008;42:423-36.

97. Lehmann D, Skrandies W. Reference-free identification of components of checkerboard-evoked multichannel potential fields. Electroencephalogr Clin Neurophysiol. 1980;48:609-21.

98. Koenig T, Kottlow M, Stein M, Melie-Garcia L. Ragu: a free tool for the analysis of EEG and MEG event-related scalp field data using global randomization statistics. Comput Intell Neurosci. 2011;2011:938925.

99. Habermann M, Weusmann D, Stein M, Koenig T. A student's guide to randomization statistics for multichannel event-related potentials using Ragu. Front Neurosci. 2018;12:355.

100. Koenig T, Melie-Garcia L, Stein M, Strik W, Lehmann C. Establishing correlations of scalp field maps with other experimental variables using covariance analysis and resampling methods. Clin Neurophysiol. 2008;119:1262-70.

101. Pascual-Marqui RD. Standardized low resolution brain electromagnetic tomography (sLORETA): technical details. Meth Find Exp Clin Pharmacol. 2002;24:5-12.

102. Koenig T, Stein M, Grieder M, Kottlow M. A tutorial on data-driven methods for statistically assessing ERP topographies. Brain Topogr. 2014;27:72-83.

103. Schiller B, Gianotti LR, Baumgartner T, Nash K, Koenig T, Knoch D. Clocking the social mind by identifying mental processes in the IAT with electrical neuroimaging. Proc Natl Acad Sci U S A. 2016;113:2786-91.

104. Williams JK, Themanson JR. Neural correlates of the implicit association test: evidence for semantic and emotional processing. Soc Cogn Affect Neurosci. 2011;6:468-76

105. Fleischhauer M, Strobel A, Diers K, Enge S. Electrophysiological evidence for early perceptual facilitation and efficient categorization of self-related stimuli during an Implicit Association Test measuring neuroticism.

Psychophysiology. 2014:51:142-51.
106. Coates MA, Campbell KB. Event-related potential measures of processing during an Implicit Association Test. Neuroreport. 2010;21:1029-33.

107. Lindgren KP, Neighbors C, Teachman BA, Wiers RW, Westgate E, Greenwald AG. I drink therefore I am: validating alcohol-related implicit association tests. Psychol Addict Behav. 2013;27:1-13.

\section{Publisher's Note}

Springer Nature remains neutral with regard to jurisdictional claims in published maps and institutional affiliations.
Ready to submit your research? Choose BMC and benefit from:

- fast, convenient online submission

- thorough peer review by experienced researchers in your field

- rapid publication on acceptance

- support for research data, including large and complex data types

- gold Open Access which fosters wider collaboration and increased citations

- maximum visibility for your research: over $100 \mathrm{M}$ website views per year

At BMC, research is always in progress.

Learn more biomedcentral.com/submissions 